\title{
The relationship between urologic cancer outcomes and national Human Development Index: trend in recent years
}

\author{
Xiao-Fang Xia ${ }^{1 \dagger}$, Yi-Qiu Wang ${ }^{3 \dagger}$, Shi-Yi Shao ${ }^{2}$, Xin-Yu Zhao ${ }^{2}$, Shi-Geng Zhang ${ }^{1}$, Zhong-Yi Li ${ }^{1}$, Yi-Chu Yuan ${ }^{*}$ and
} Nan Zhang ${ }^{1 *}$

\begin{abstract}
Objectives: To describe the influence of the socioeconomic development on worldwide age-standardized incidence and mortality rates, as well as mortality-to-incidence ratio (MIR) and 5-year net survival of urologic cancer patients in recent years.

Methods: The Human Development Index (HDI) values were obtained from the United Nations Development Programme, data on age-standardized incidence/mortality rates of prostate, bladder and kidney cancer were retrieved from the GLOBOCAN database, 5-year net survival was provided by the CONCORD-3 program. We then evaluated the association between incidence/MIR/survival and HDI, with a focus on geographic variability as well as temporal patterns during the last 6 years.

Results: Urologic cancer incidence rates were positively correlated with HDls, and MIRs were negatively correlated with HDIs. Prostate cancer survival also correlated positively with HDIs, solidly confirming the interrelation among cancer indicators and socioeconomic factors. Most countries experienced incidence decline over the most recent 6 years, and a substantial reduction in MIR was observed. Survival rates of prostate cancer have simultaneously improved.

Conclusion: Development has a prominent influence on urologic cancer outcomes. HDI values are significantly correlated with cancer incidence, MIR and survival rates. HDI values have risen along with increased incidence and improved outcomes of urologic caner in recent years.
\end{abstract}

Keywords: Urologic cancer, Human Development Index, Incidence, Mortality, Survival

\section{Introduction}

With the growing and aging population, cancer has been expected to rank as the leading cause of death and the most important barrier to increasing life expectancy across the world [1]. Urologists are the front line for the diagnosis and treatment of urologic malignancies, mainly including prostate, bladder, and kidney cancer

\footnotetext{
*Correspondence: ycyuan@zju.edu.cn; nanzhang@zju.edu.cn

${ }^{\dagger}$ Xiao-Fang Xia and Yi-Qiu Wang have contributed equally to this work

1 Department of Urology, The Second Affiliated Hospital, Zhejiang

University School of Medicine, Hangzhou 310009, China

Full list of author information is available at the end of the article
}

[2]. According to Global Cancer Statistics 2018, prostate, bladder and kidney cancers have ranked the 3rd, 10th and 14th most common tumors worldwide with crude incidence rate (per 100,000) of 36.0, 7.4 and 5.5, respectively [1]. The main epidemiologic characteristics of urologic cancer are impacted by the large geographic and temporal variation in risk factors related with behavioral, environmental and socioeconomic reasons [2]. Meanwhile, the global composition of urologic cancer patients has been continuously evolving due to multiple forces [1-9].

Socioeconomic development is closely interconnected with public health [10]. Human Development Index 
(HDI) is the gold standard for the comparison of socioeconomic development, quantified by the composite measures of health, education, and economy [11]. Multiple studies had demonstrated that cancer outcomes were related with HDI $[12,13]$. Some identified there was a negative correlation between standardized mortality rates and HDI [14] but others verified no significant correlation [15]. The impact of national HDI on outcomes of urologic malignancies has not been characterized on a global scale. Furthermore, the different urologic cancer profiles in individual countries signify that marked geographic diversity still exists nowadays, with a persistence of local factors in populations at quite unbalanced phases of social and economic transition. But the global distribution and transition of urologic neoplasms under social development and medical advances in recent years are still not clarified.

This study aims to evaluate the correlation between the HDI values and the incidence rates, mortality-to-incidence ratio (MIR) and 5-year survival rates of urologic cancer in 2012 and 2018.

\section{Materials and methods}

\section{Data sources}

Several databases providing reliable data and resources were adopted in this study. The GLOBOCAN database (http://gco.iarc.fr), maintained by the International Agency for Research on Cancer (IARC), provides highquality registry data of cancer incidence and mortality at the global level, while the CONCORD-3 program is regarded as the largest and most up-to-date study of international cancer survival trends. The United Nations Development Programme (UNDP) database (http://hdr. undp.org/en/statistics) provides human development indicators across multiple dimensions and for every nation, giving an overview of the state of development worldwide.

The incidence and mortality estimates of urologic cancer were originally extracted from the GLOBOCAN database. Patients with urologic cancer were identified by ICD-10 (International Statistical Classification of Diseases and Related Health Problems-10th Revision codes C00-C97) codes for prostate (C61), bladder (C67), and kidney (C64-65, including renal pelvis). Data within 186 countries in 2018 and 175 countries in 2012 were incorporated. The incidence and mortality data were age-standardized rates (ASRs) per 100,000 person-years. The ASRs were calculated according to the world standard population, allowing comparisons between populations without being influenced by differences in their age structures $[1,16]$.

HDI data for United Nations members of 2012 and 2018 were publicly available in the UNDP database.
Countries then were divided into 4 subgroups according to HDI levels by the UNDP (very-high, high, medium and low HDI) [11].

We further collected the 5-year net survival estimates of patients diagnosed with prostate cancer during the 2005-2009 and 2010-2014 periods from the CONCORD-3 report which corresponded with patient status in year 2012 and 2018 [17]. Net survival is the cumulative probability of surviving up to a given time since diagnosis (e.g., 5 years) after correcting for other causes of death (background mortality) [17]. The net survival estimates were also age-standardized by the International Cancer Survival Standard weights [18].

\section{Statistical analysis}

With the obtained incidence and mortality rates, we calculated the prostate, bladder and kidney cancer mortality-to-incidence ratios (MIR) (i.e., cancer deaths divided by incident cancer cases). Extreme values (0, 1 or $>1$ ) were considered abnormal and were excluded from the analysis. To examine patterns in the MIR of urologic cancer by levels of socioeconomic development, we correlated the MIRs to the corresponding HDIs via linear and nonlinear regression. Linear regression fit was conducted to identify the existence of correlation. Correlation was established with a significant $p$ value in the nonparametric Spearman correlation test. Nonlinear regression was based on a modified "dose-to-response" model using the formula

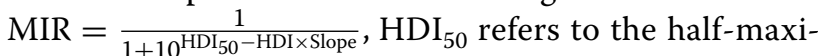
mal controlled HDI (equivalent to the HDI value at half-maximal MIR) and slope is a parameter indicating the steepness of the fitted curve. MIRs comparison among 4-tier HDI groups was analyzed via One-way ANOVA followed by Tukey-Kramer post hoc tests. We further examined the correlation of national incidence rates and 5-year net survival estimates with corresponding HDI, separately. In order to determine the effects of socioeconomic transitions on urologic cancer outcomes, we further compared the age-standardized MIR or 5-year net survival estimates in the year of 2012 and 2018 (paired t-test). A $p$ value less than 0.05 was considered statistically significant. Statistical analysis and plotting were performed using Prism 7 (GraphPad, San Diego, CA).

Global geographical maps showing the gradient distribution of HDI values, incidence, mortality, calculated MIR, and survival estimates were depicted by TileMill (a GitHub software maintained by MapBox, Washington, DC), with map data sources from the Natural Earth database rendered by the Mapnik Library (https://mapnik. $\operatorname{org} /)$. 


\section{Result}

Overview of current global urologic cancer epidemiology The data of 174 countries available both in the 2018 GLOBOCAN database and 2018 HDI statistics were incorporated. Development levels of countries were classified into 4 classes according to HDI values by the UNDP (Fig. 1a). The global age-standardized incidence and mortality rates of prostate, bladder and kidney cancer in 2018 were presented separately (Additional file 1: Fig. S1a-f). Mortality-to-incidence ratios (MIRs) were calculated for prostate, bladder and kidney cancer and their global distribution was depicted in the form of world maps (Fig. 1b-d). It is estimated that there will be almost 1.8 million new cases of urologic cancer and 616,000 associated deaths worldwide in 2018, showing slightly decreasing tendency compared with $2012(2.2$ million new cases and 734,000 deaths). The global MIR of urologic cancer was 0.282 in 2018 and 0.286 in 2012, with almost no fluctuation.
Prostate cancer had a cumulative 1.3 million new cases and 359,000 deaths worldwide in 2018, ranking as the second most frequent cancer in men. The top countries with the highest incidence rates of prostate cancer were all in very-high HDI group (Additional file 1: Fig. S1a), including Europe (e.g., Ireland, Estonia, Norway, Sweden, France, United Kingdom, Czech Republic, Latvia, Slovenia, Luxembourg, Switzerland, Denmark), North America (United States), Australia/ New Zealand, and Barbados. However, mortality rates did not follow those of incidence. The highest mortality rates fell mainly in countries with lower HDI (Additional file 1: Fig. S1b), including the Caribbean (e.g., Barbados, Jamaica, Haiti, Saint Lucia, Bahamas, Trinidad and Tobago) and Africa (e.g., Benin, Cabo Verde, Zimbabwe, Liberia, Côte d'Ivoire). The calculated MIRs ranged from 0.081 (France) to 0.844 (Afghanistan). The lowest MIRs were achieved in highly developed countries (Fig. 1b), such as France, Ireland, Italy, Spain, United States, Luxemburg, Israel, Australia, and Japan. Whereas low-to-medium

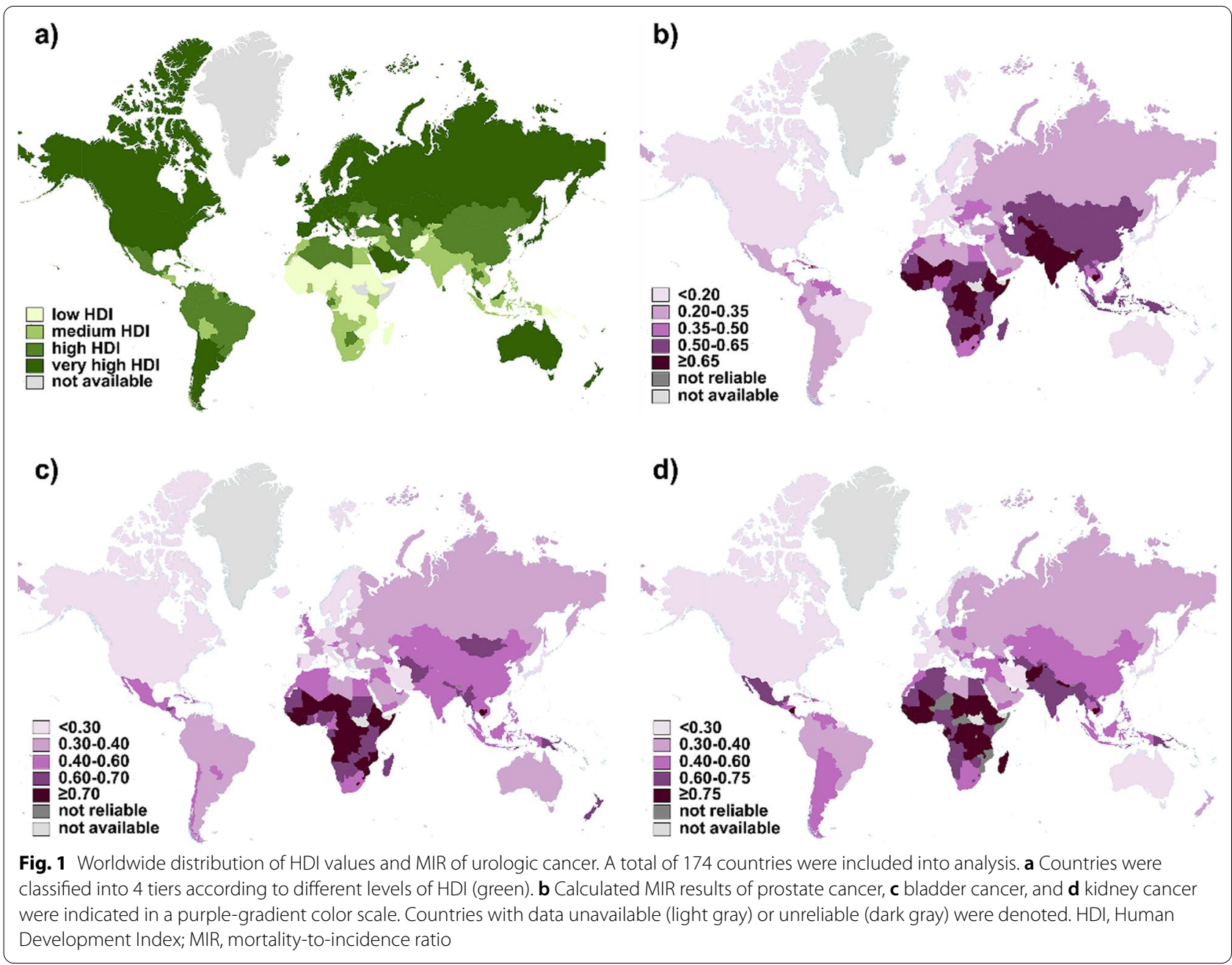


HDI countries owned the highest MIRs (Afghanistan, Guinea, Pakistan, Liberia, Uzbekistan, Cambodia and Nepal).

It was estimated that bladder cancer ranked the 10th most common cancer with 549,000 new cases and 200,000 deaths in 2018. Bladder cancer was most common to happen in high-to-very high HDI regions (Additional file 1: Fig. S1c), especially European countries (Greece, Denmark, Hungary, Netherlands, Albania, Italy, Germany, Spain), although the highest rates were in Lebanon. However, the top 10 countries with highest MIRs of bladder cancer were all from low-HDI group (Fig. 1c), consisting of Africa (Niger, Comoros, Central African, Djibouti, Liberia, Guinea-Bissau, Guinea, Uganda, Chad) and Timor-Leste. The lowest MIR was 0.119 in Iceland.

403,000 cases of kidney cancer and 175,000 related deaths occurred in 2018. New kidney cancer diagnoses were made most in very-high HDI European countries (Additional file 1: Fig. S1e) (Belarus, Latvia, Lithuania, Czech Republic, Estonia, Slovakia, France, Hungary, Iceland, Croatia). Similarly, the distribution of MIRs of kidney cancer was from 0.165 (Korea) to 0.950 (Mali) (Fig. 1d). The lowest MIRs were achieved in very-high HDI group like Korea, Bahamas, Luxembourg, United States, Canada, Norway, Italy, Australia, and Japan. While the lowest were obtained from low-HDI African countries (Mali, Chad, South Sudan, Burkina Faso, Guinea, Sierra Leone, Eritrea).

\section{The correlation between urologic cancer MIR and national HDI}

The global MIR of prostate, bladder and kidney cancer in 2018 was $0.358,0.251$, and 0.410 , respectively (Fig. 1b-d). As the above described distribution of urologic cancer MIR and developing degree, we analyzed their relationship in mathematical regression. We found that as the level of national HDI increased, the corresponding urologic cancer MIR was relatively lower, with strong correlation (prostate: $r=-1.059, p<0.0001$ for 2018, $r=-1.425, p<0.0001$ for 2012; bladder: $r=-1.049$, $p<0.0001$ for 2018, $r=-0.918, p<0.0001$ for 2012; kidney: $r=-1.153, p<0.0001$ for 2018, $r=-1.231$, $p<0.0001$ for 2012). We also applied nonlinear regression analysis on data, verifying the existence of a "doseto-response" inhibitory effect between HDI values and MIRs (Fig. 2a, b, d-e, g, h). The HDI values at half maximal MIR ( $\mathrm{HDI}_{50}$ ) of prostate, bladder and kidney cancer in 2018 was $0.639,0.704$ and 0.736 , respectively.

We further compared the MIRs of urologic cancer among 4-tier HDI groups and clarified the persistent disparities associated with HDI levels $(p<0.0001$, Oneway ANOVA). Take prostate cancer in 2018 for example, the mean MIR in very-high HDI countries (0.224) was significantly lower than that in high- (0.424), medium(0.522), or low- (0.641) HDI countries $(p<0.0001$, Tukey's post hoc test; Fig. 2c). Similar results were obtained in other cancer sites (bladder, kidney) as well as data in 2012 $(p<0.0001$, Tukey's post hoc test; Fig. 2f, i).

\section{Association between incidence rates of urologic cancer and HDI}

Since the fact that urologic cancers tended to happen more in high-to-very high-HDI countries, we also applied correlation analysis on the association between incidence rates and HDI. It was demonstrated that national incidence rates in urologic cancer all had strong correlation with corresponding HDIs via linear regression $(r>0$, $p<0.0001$; Fig. 3a-c).

\section{The impact of HDI on 5-year survival of prostate cancer}

The 5-year net survival rates were available in 57 countries for prostate cancer in CONCORD-3 program (Fig. 4a). Similar to MIRs, patients diagnosed during 2010-2014 from very-high-HDI countries like Cyprus (99.2\%), United States (98.1\%) and Israel (95.6\%) topped in survival rates. While countries with limited developments, like South Africa (37.8\%), India (44.3\%) and Nigeria (58.7\%), fell far behind other regions. We then investigated the association between survival rates and HDI. Cross-national analysis demonstrated that survival rates of patients diagnosed in 2010-2014 correlated positively with HDI values via linear regression $(r=1.084$, $p<0.0001$; Fig. 4b). Accordingly, the survival rates correlated inversely with national MIR $(r=-0.730, p<0.0001$; Fig. 4c).

\section{Temporal transition of urologic cancer burdens and outcomes from 2012 to 2018}

It was reported that urologic cancers had a cumulative 2.1 million new cases worldwide in 2013 , nearly 2.5 -fold the number in 1990 [2]. Our study updated the transition of urologic cancer outcomes from 2012 to 2018 with latest data. Also, the calculated summary statistics were listed in Table 1.

\section{Prostate cancer}

Incidence and mortality rates of prostate cancer have risen considerably since the end of last century [2]. Nevertheless, it should be noted that between 2012 and 2018, new prostate cases decreased from 1,276,706 to $1,111,689$, and fell from 358,989 to 307,417 in deaths. In general, the MIR of prostate cancer did not change much during the past 6 years $(0.251 v s 0.259)$. We plotted national HDIs and MIRs in 2018 and 2012 together and noticed similar distributions (Fig. 5a). Notably, there is an evident change that linear regression line has shifted 

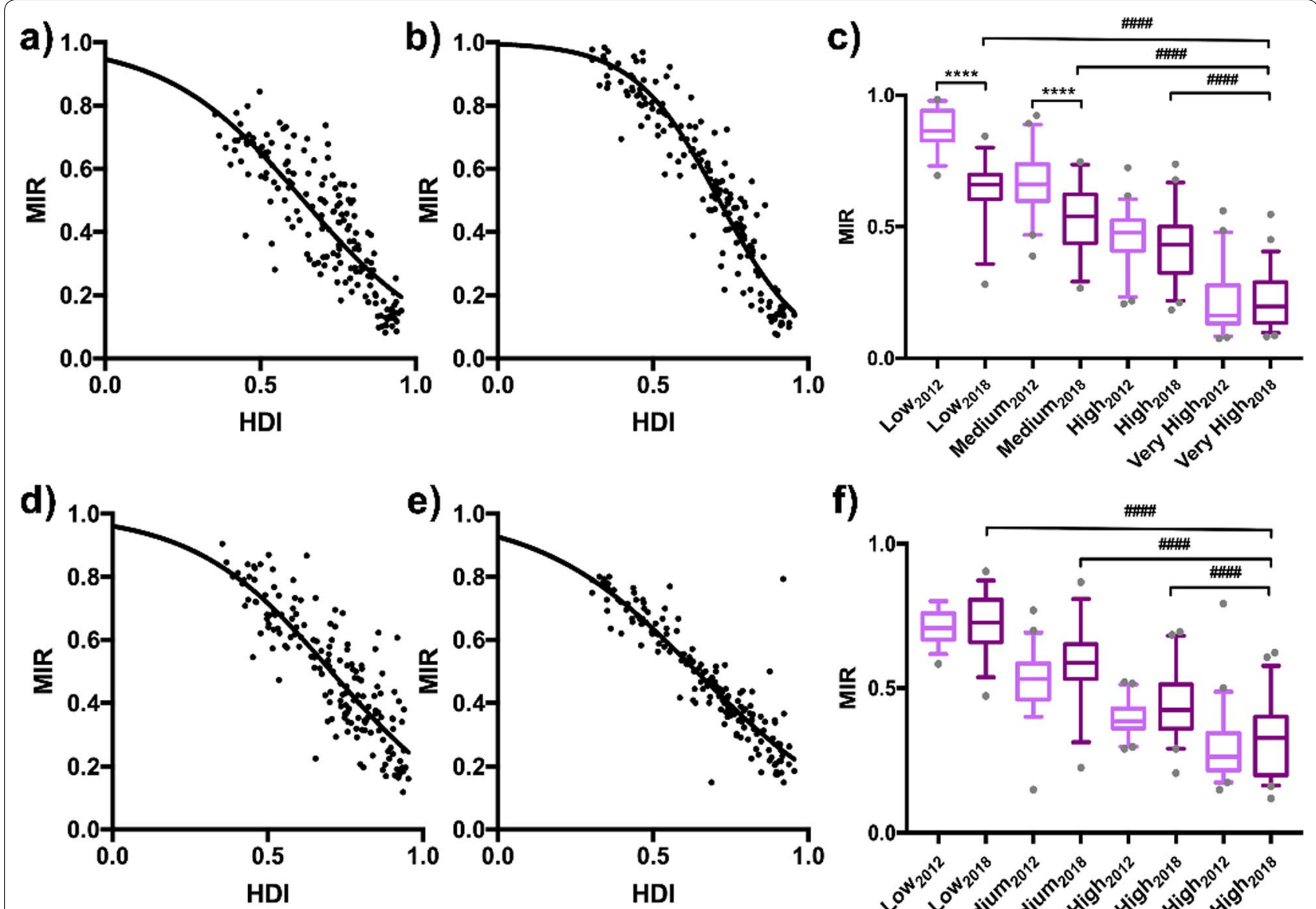

e)

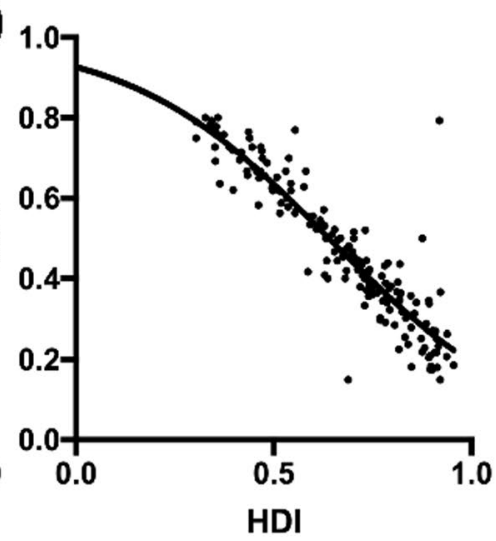

f)
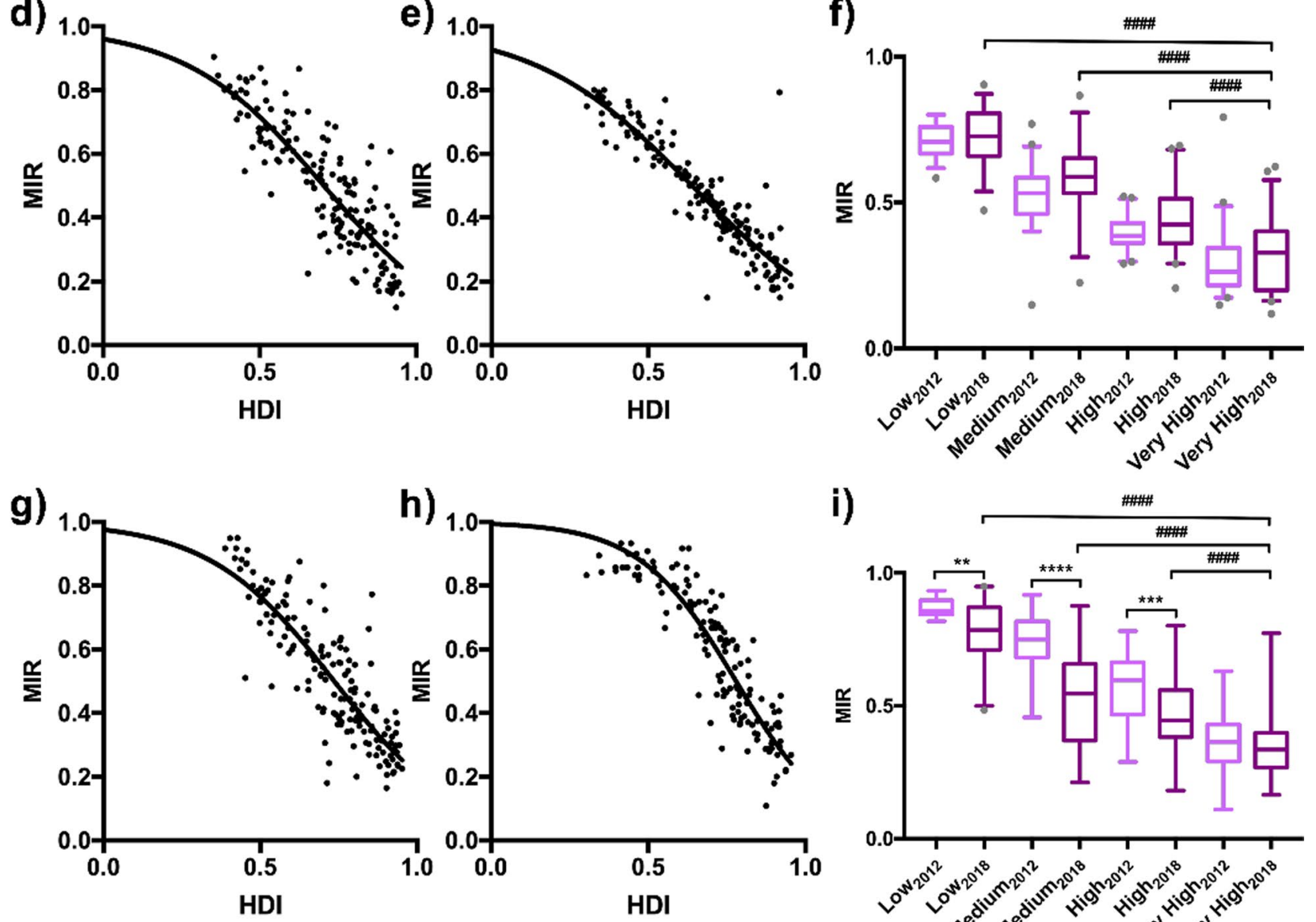

h)
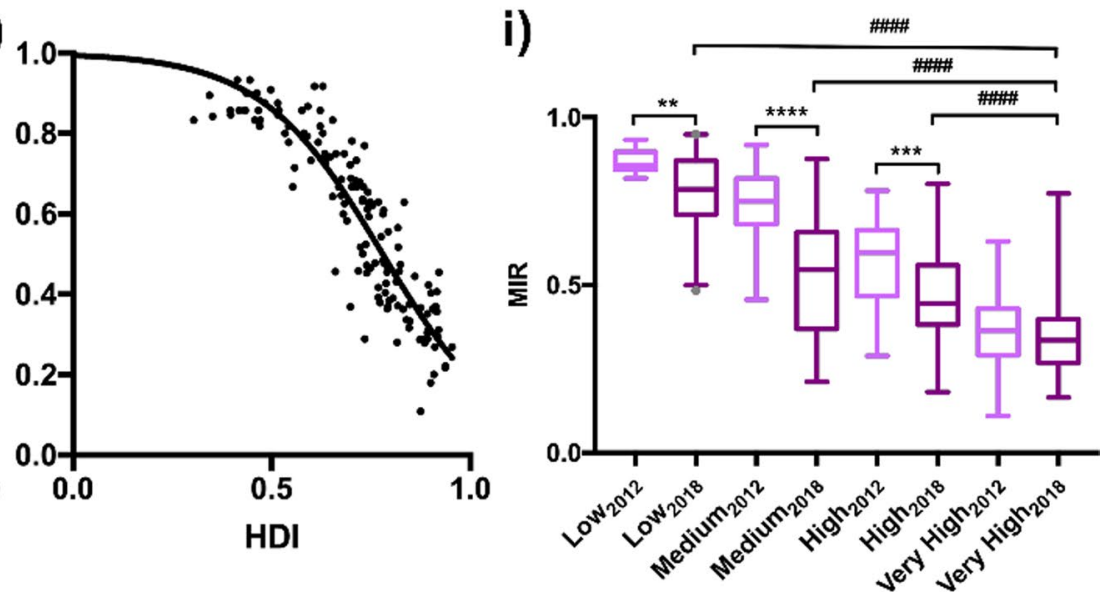

Fig. 2 Correlation between HDI and MIR and its transition from 2012 to 2018. The patterns of urologic cancer MIRs to national HDIs with the best-fit lines by modified nonlinear regression ("dose-to-response" model) were presented as following: a prostate cancer in 2018 (slope $=-1.962$, $\left.\mathrm{HDI}_{50}=0.639, \mathrm{R}^{2}=0.687\right)$ and $\mathbf{b}$ in $2012\left(\mathrm{slope}=-3.177, \mathrm{HDI}_{50}=0.713, \mathrm{R}^{2}=0.891\right) ; \mathbf{d}$ bladder cancer in 2018 (slope $=-1.967, \mathrm{HDI}_{50}=0.704$, $\mathrm{R}^{2}=0.733$ ) and $\mathbf{e}$ in 2012 (slope $\left.=-1.720, \mathrm{HDI}_{50}=0.640, \mathrm{R}^{2}=0.835\right)$; $\mathbf{g}$ kidney cancer in 2018 (slope $\left.=-2.178, \mathrm{HDI}_{50}=0.736, \mathrm{R}^{2}=0.737\right)$ and $\mathbf{h}$ in 2012 (slope $=-2.835, \mathrm{HDI}_{50}=0.780, \mathrm{R}^{2}=0.824$ ). MIRs of $\mathbf{c}$ prostate, $\mathbf{f}$ bladder and $\mathbf{i}$ kidney cancer in the $4 \mathrm{HDI}$ groups, with significant differences among the very high, high, medium and low groups and a decreasing tendency in certain groups between 2012 (light purple) and 2018 (dark purple). \#\#\# p<0.0001, vs. very-high-HDI countries in 2018, one-way ANOVA followed by Tukey-Kramer post hoc test. The statistical significance among countries in 2012 was not indicated. ${ }^{* *} p<0.01,{ }^{* * *} p<0.001,{ }^{* * *} p<0.0001,2008$ vs. 2018 in specific corresponding group, unpaired t-test 


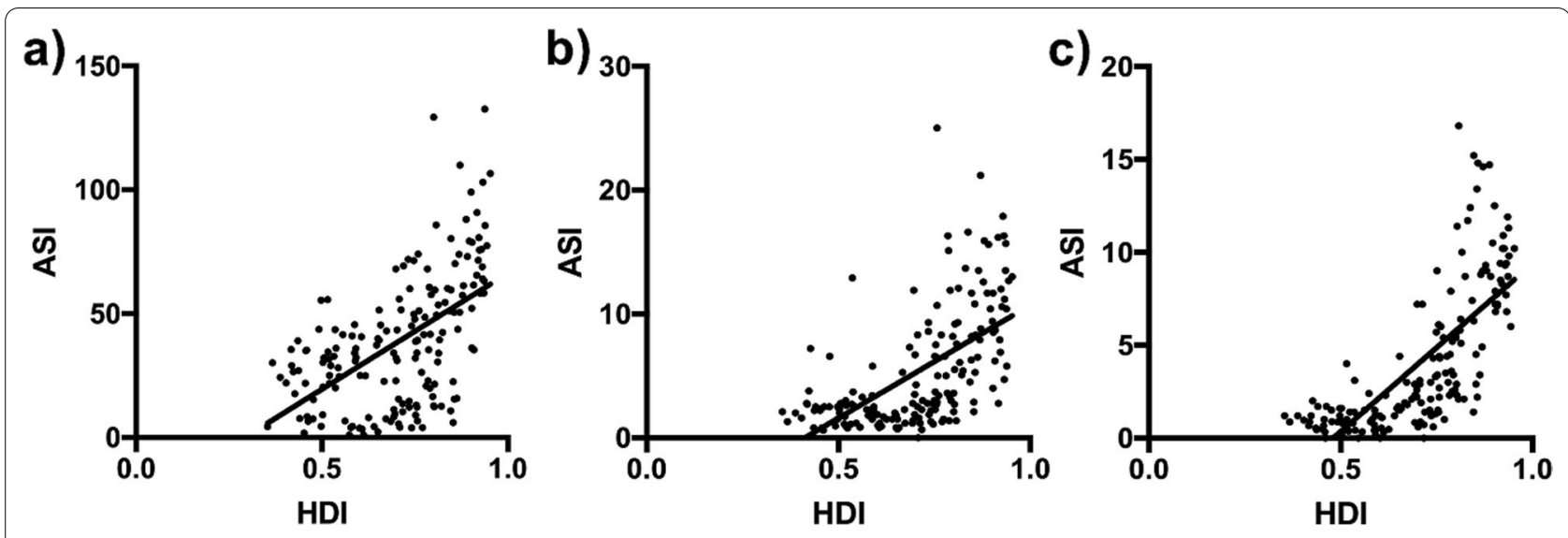

Fig. 3 The association between incidence rates of urologic cancers and HDI. a The national age-standard incidence rates of prostate cancer correlated positively $(r=0.556, p<0.0001)$ with HDIs via linear regression (slope $=93.54)$ in 2018 . Similar results for $\mathbf{b}$ bladder cancer $(r=0.661$, $p<0.0001$, slope $=18.22)$ and $\mathbf{c}$ kidney cancer $(r=0.816, p<0.0001$, slope $=18.06)$

to the lower-left direction from 2012 to 2018, most obviously among countries with lower HDIs. Furthermore, within both low- and medium- HDI groups, the national MIRs in 2018 decreased significantly in comparison to the 2012 data $(p<0.0001$ for both groups, Mann-Whitney test; Fig. 2c). In high HDI groups, there was only decreasing tendency without significance $(0.424$ vs 0.460 , $p>0.05$; Fig. 2c). The survival rates generally increased, with only 7 out of 57 countries dropped more than $1 \%$ $(p<0.05$; paired t-test) (Fig. 5b; Table 2).

\section{Bladder cancer}

New bladder cancer diagnoses shrank nearly a quarter between 2012 and 2018 (549 393 vs 429 793). It is remarkable that MIR of bladder cancer in 2018 had a slight increase when compared with 2012, though not significantly (0.358 vs $0.333 ; p>0.05$, Fig. 2 f, Fig. $5 c)$. There was also only tiny fluctuation between MIR of 2012 and 2018 within each specific HDI group (Fig. 2f).

\section{Kidney cancer}

The incidence of kidney cancer also reduced during 2012-2018 (337 860 vs 403 262). In the scatter diagram of HDI-MIR, current MIR of kidney cancer also shifted in the direction of lower-left when comparing with 2012 (Fig. 5d). Remarkably, two regression lines were nearly parallel $\left(\mathrm{r}_{2018}=-1.153, \mathrm{r}_{2012}=-1.231 ; p<0.01\right.$, Mann-Whitney test). Meanwhile, MIRs of kidney cancer declined overall, across all development status $(p<0.01$ for the low-, $p<0.0001$ for the medium-, $p<0.001$ for the high-, and $p=0.23$ for the very-high-HDI group, MannWhitney test; Fig. 2i).

\section{Discussion}

Our study aims to clarify the latest epidemiology of urologic cancer and the contribution of national development to urologic cancer outcomes. We adopted Human Development Index (HDI) to evaluate development, a composite index focusing on three basic dimensions of socioeconomic development: life expectancy, years of schooling, and gross national income per capita [11]. Mortality-to-incidence ratio (MIR) and 5-year net survival both represent cancer outcomes. MIR is regarded as a quite useful surrogate indicator of oncology care effectiveness, which could be a comprehensive result of screening, diagnostic modality, treatment and follow-up $[12,19]$. Meanwhile, 5-year net survival might be labeled with more importance, since cancer patients who survive for a considerable time span can, in a way, be considered cured $[17,20]$. In the current study, we proved that all three urologic cancers MIR negatively, while incidence and survival rates positively correlated with HDI. Our study investigated the trends in the global burden of urologic cancer from 2012 to 2018. HDI values raised along with the decline in corresponding incidence and MIRs, as well as improvement in survival.

\section{Prostate cancer}

Incidence of prostate cancer was highest in countries with very-high HDI, like Europe, North America, Australia/New Zealand, as well as Barbados and Bahamas. The public recommendation and prevalence of early diagnostics for prostate cancer in more developed countries, by PSA testing and detection of latent cancer in transurethral prostatectomy or puncture biopsy, led to higher incidence rates. For example, the commercial availability of PSA testing from 1980s brought about the intensively 

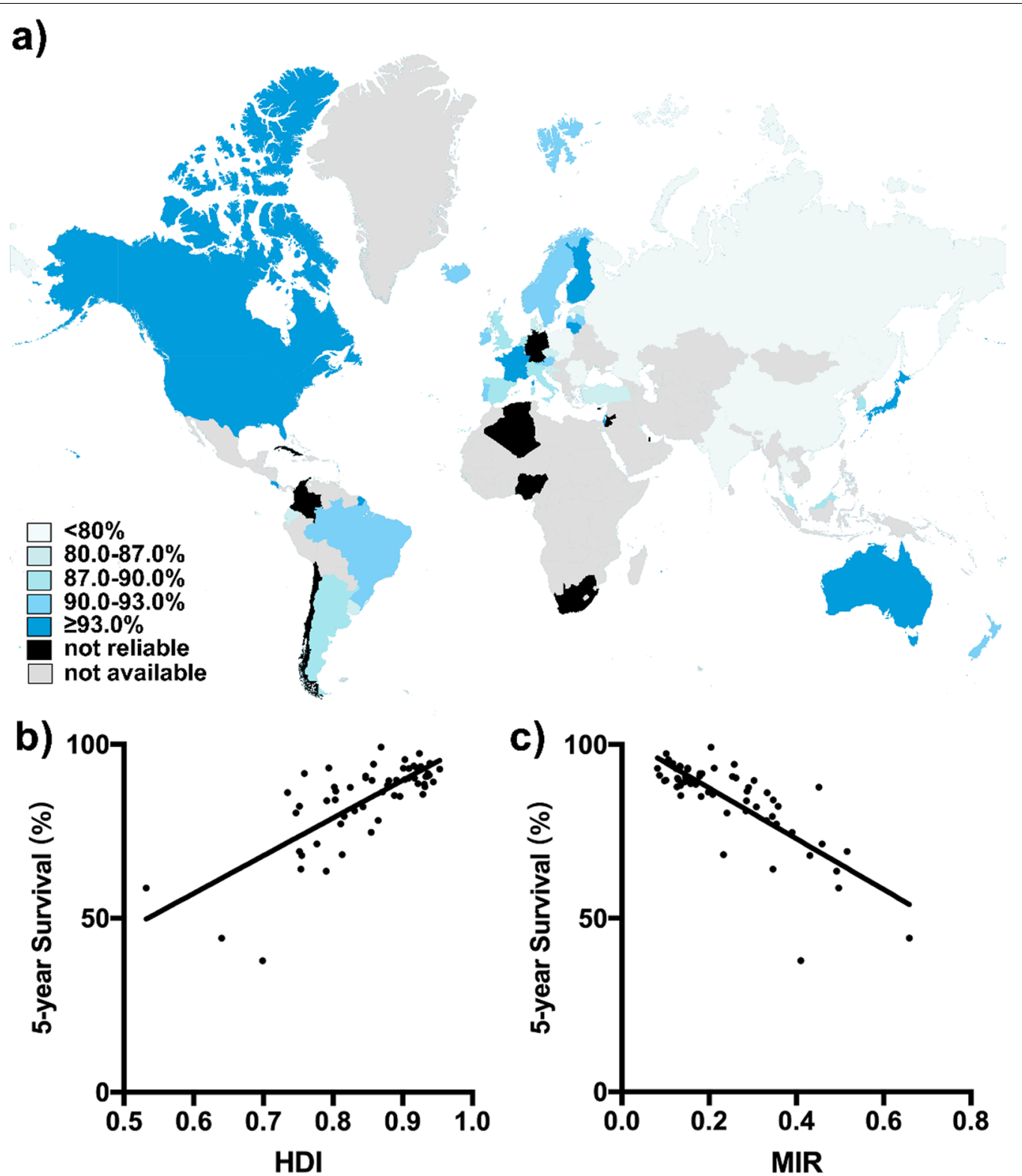

Fig. 4 Distributions of prostate cancer survival and its correlation with HDI values and MIRs. a Distribution of regional estimated 5-year net survival for patients with prostate cancer in 2018, indicated in blue-gradient colors. $\mathbf{b}$ A positive correlation pattern between the survival of the patients diagnosed in 2010-2014 and the HDI value in $2018(r=0.669, p<0.0001$, slope $=108.4)$. c Correlation between national MIR and survival of prostate cancer in $2018(r=-0.749, p<0.0001$, slope $=-72.97)$

use of the test and rapid growth in new cases, first in the United States and within a few years, in Europe, Australia/New Zealand, and Canada [1, 21, 22]. Another explanation could be attributed to age. Nearly $75 \%$ of new prostate cancer cases occurring in people aged over 85 years, and incidence of prostate cancer is directly correlated with age $[15,23]$. Since life expectancy is one of key elements of HDI, there is no doubt that countries with higher HDI had a greater prostate cancer incidence.
Moreover, ethnic and genetic predisposition could also be blamed for prostate cancer morbidity. The rates are highest among men of African descent in the United States and the Caribbean [24]. That's why Barbados and Bahama topped in the incidence rates of prostate cancer with a relatively lower HDI within high-HDI group.

Based on previous study, we demonstrated an inverse correlation of MIR and a positive association between survival and HDI. The non-linear regression analysis 
Table 1 Summary statistics of all variables of bladder, prostate and kidney cancer

\begin{tabular}{|c|c|c|c|c|c|c|c|c|}
\hline \multirow[b]{2}{*}{ Cancer type } & \multicolumn{4}{|l|}{2012} & \multicolumn{4}{|l|}{2018} \\
\hline & HDI & ASI & MIR & Survival & HDI & ASI & MIR & Survival \\
\hline prostate & $\begin{array}{l}0.669 / 0.702 \\
(0.519-0.805)\end{array}$ & $\begin{array}{l}41.0 / 35.4 \\
(16.2-58.3)\end{array}$ & $\begin{array}{l}0.542 / 0.543 \\
(0.338-0.777)\end{array}$ & $\begin{array}{l}82.2 / 87.3 \\
(76.6-91.1)\end{array}$ & $\begin{array}{l}0.705 / 0.735 \\
(0.582-0.826)\end{array}$ & $\begin{array}{l}38.7 / 35.2 \\
(15.8-55.8)\end{array}$ & $\begin{array}{l}0.432 / 0.434 \\
(0.276-0.606)\end{array}$ & $\begin{array}{l}84.1 / 88.2 \\
(80.6-91.4)\end{array}$ \\
\hline bladder & & $\begin{array}{l}5.32 / 3.2 \\
(1.90-7.95)\end{array}$ & $\begin{array}{l}0.473 / 0.444 \\
(0.347-0.631)\end{array}$ & NA & & $\begin{array}{l}5.31 / 3.00 \\
(1.90-8.13)\end{array}$ & $\begin{array}{l}0.497 / 0.497 \\
(0.344-0.643)\end{array}$ & NA \\
\hline kidney & & $\begin{array}{l}4.05 / 2.60 \\
(1.20-6.05)\end{array}$ & $\begin{array}{l}0.582 / 0.604 \\
(0.386-0.780)\end{array}$ & NA & & $\begin{array}{l}4.04 / 2.30 \\
(1.19-6.43)\end{array}$ & $\begin{array}{l}0.518 / 0.492 \\
(0.360-0.684)\end{array}$ & NA \\
\hline
\end{tabular}

The statistics are presented as mean/median (inter quartile range). HDI, Human Development Index. ASI: Age-Standardized Incidence. MIR, Mortality-to-Incidence Ratio
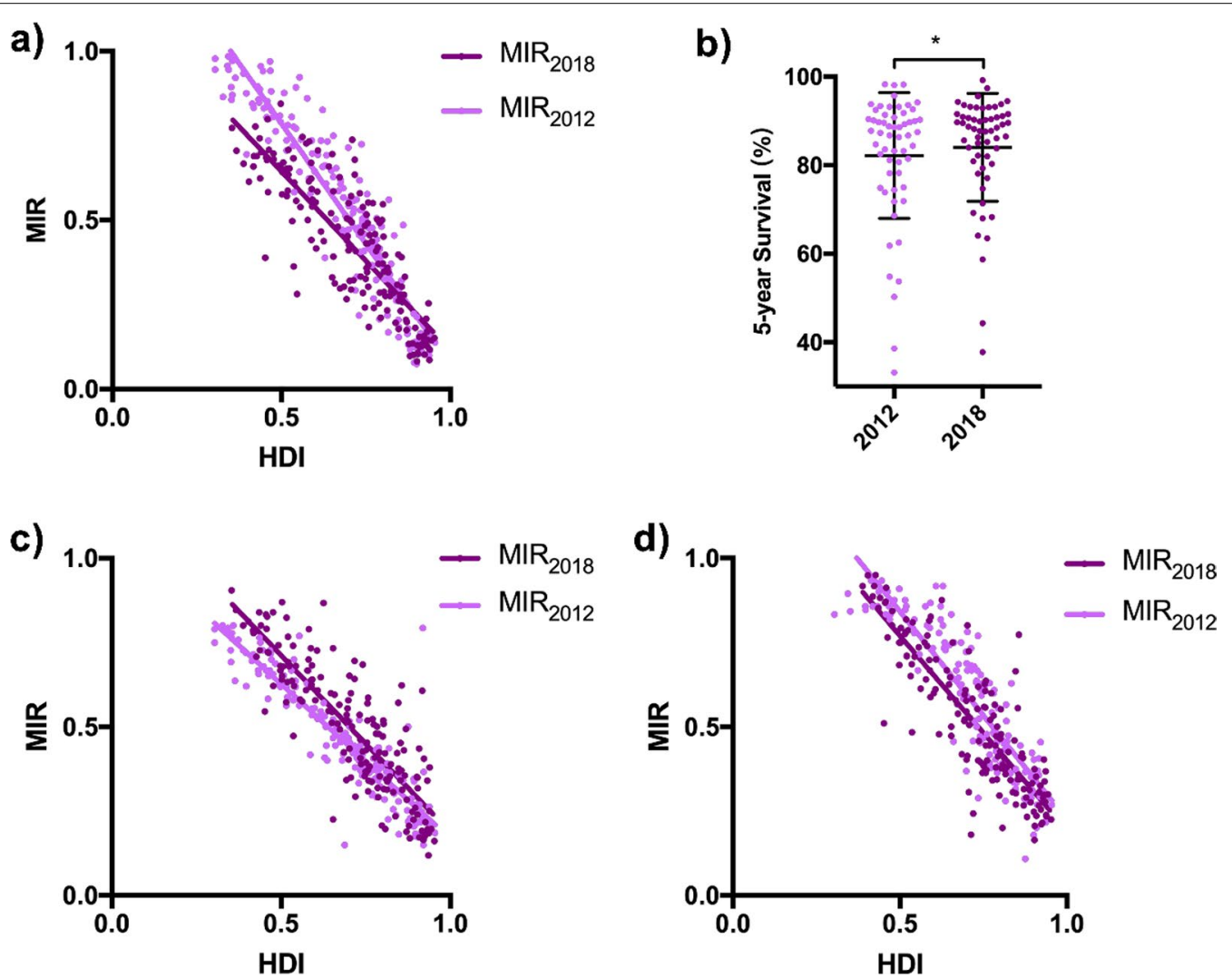

Fig. 5 Urologic cancer outcomes and its trend from 2012 to 2018. Transition of the correlation patterns of a prostate cancer MIR to national HDI from 2012 (light purple, $r=-0.617, p<0.0001$ ) to 2018 (dark purple, $r=-0.548, p<0.0001$ ), $\mathbf{c}$ bladder cancer from 2012 to 2018 , as well as $\mathbf{d}$ kidney cancer from 2012 to 2018, showing a declining tendency of MIRs within the decade. b Significant increase in overall survival rates in 57 overlapping countries from 2012 (light purple) to 2018 (dark purple). ${ }^{*} p<0.05$, paired t-test

confirmed the "dose-to-response" effect between HDI and MIR. The relationship between HDI and MIR bears a similarity to the dose-dependent inhibitory response by drugs because of the existence of several characteristics in common, like (1) MIR or response approaches 1 as HDI or dose approaches 0; (2) MIR or response decreases as HDI or dose increases; and (3) MIR or response approaches 0 as HDI or dose approaches infinity. The impact of HDI on cancer outcomes seemed to be driven by national inequalities in health care, resulting in deviations in treatment effectiveness. First of all, the widespread access to diagnostic services and screening tests in more developed countries leads to increased diagnosis at earlier stages of disease and better clinical outcomes. 
Table 2 National HDI and 5-year net survival values of prostate cancer from 2012 to 2018

\begin{tabular}{|c|c|c|c|c|c|c|}
\hline \multirow[t]{2}{*}{ Country } & \multicolumn{2}{|l|}{2012} & \multicolumn{2}{|l|}{2018} & \multicolumn{2}{|c|}{ Transitions in a decade } \\
\hline & HDI & Survival & HDI & Survival & $\Delta_{\mathrm{HDI}}$ & $\Delta_{\text {survival }}$ \\
\hline Algeria & 0.713 & 50.3 & 0.754 & 64.1 & 0.041 & 13.8 \\
\hline Argentina & 0.811 & 83.6 & 0.825 & 87.6 & 0.014 & 4 \\
\hline Australia & 0.938 & 93.2 & 0.939 & 94.5 & 0.001 & 1.3 \\
\hline Austria & 0.895 & 90.8 & 0.908 & 90.2 & 0.013 & -0.6 \\
\hline Belgium & 0.897 & 93.2 & 0.916 & 93.8 & 0.019 & 0.6 \\
\hline Brazil & 0.73 & 92.5 & 0.759 & 91.6 & 0.029 & -0.9 \\
\hline Bulgaria & 0.782 & 54.8 & 0.813 & 68.3 & 0.031 & 13.5 \\
\hline Canada & 0.911 & 94.2 & 0.926 & 93.6 & 0.015 & -0.6 \\
\hline Chile & 0.819 & 84.4 & 0.843 & 82 & 0.024 & -2.4 \\
\hline China & 0.699 & 62.5 & 0.752 & 69.2 & 0.053 & 6.7 \\
\hline Colombia & 0.719 & 87.8 & 0.747 & 80.3 & 0.028 & -7.5 \\
\hline Costa Rica & 0.773 & 92.6 & 0.794 & 93.2 & 0.021 & 0.6 \\
\hline Croatia & 0.805 & 78.3 & 0.831 & 80.9 & 0.026 & 2.6 \\
\hline Cuba & 0.78 & 53.8 & 0.777 & 71.4 & -0.003 & 17.6 \\
\hline Cyprus & 0.848 & 98.3 & 0.869 & 99.2 & 0.021 & 0.9 \\
\hline Czech Republic & 0.873 & 81.5 & 0.888 & 85.3 & 0.015 & 3.8 \\
\hline Denmark & 0.901 & 82.5 & 0.929 & 85.6 & 0.028 & 3.1 \\
\hline Ecuador & 0.724 & 80.7 & 0.752 & 82.2 & 0.028 & 1.5 \\
\hline Estonia & 0.846 & 83.2 & 0.871 & 86.3 & 0.025 & 3.1 \\
\hline Finland & 0.892 & 93.4 & 0.920 & 93.2 & 0.028 & -0.2 \\
\hline France & 0.893 & 93.6 & 0.901 & 93.1 & 0.008 & -0.5 \\
\hline Germany & 0.92 & 91.8 & 0.936 & 91.6 & 0.016 & -0.2 \\
\hline Iceland & 0.906 & 89.7 & 0.935 & 90.8 & 0.029 & 1.1 \\
\hline India & 0.554 & 33.2 & 0.640 & 44.3 & 0.086 & 11.1 \\
\hline Ireland & 0.916 & 89.7 & 0.938 & 91.1 & 0.022 & 1.4 \\
\hline Israel & 0.9 & 95.7 & 0.903 & 95.6 & 0.003 & -0.1 \\
\hline Italy & 0.881 & 89.6 & 0.880 & 89.5 & -0.001 & -0.1 \\
\hline Japan & 0.912 & 91.4 & 0.909 & 93 & -0.003 & 1.6 \\
\hline Jordan & 0.7 & 88.6 & 0.735 & 86.1 & 0.035 & -2.5 \\
\hline Korea, Republic of & 0.909 & 87.3 & 0.903 & 89.9 & -0.006 & 2.6 \\
\hline Kuwait & 0.79 & 71.9 & 0.803 & 84 & 0.013 & 12.1 \\
\hline Latvia & 0.814 & 88.8 & 0.847 & 90.4 & 0.033 & 1.6 \\
\hline Lithuania & 0.818 & 93.8 & 0.858 & 94.3 & 0.040 & 0.5 \\
\hline Malaysia & 0.769 & 74.9 & 0.802 & 87.7 & 0.033 & 12.8 \\
\hline Malta & 0.847 & 86.4 & 0.878 & 88.2 & 0.031 & 1.8 \\
\hline Mauritius & 0.737 & 61.8 & 0.790 & 63.5 & 0.053 & 1.7 \\
\hline Netherlands & 0.921 & 87.5 & 0.931 & 88.5 & 0.010 & 1 \\
\hline New Zealand & 0.919 & 89.3 & 0.917 & 90.3 & -0.002 & 1 \\
\hline Nigeria & 0.471 & 73.9 & 0.532 & 58.7 & 0.061 & -15.2 \\
\hline Norway & 0.955 & 90.3 & 0.953 & 92.9 & -0.002 & 2.6 \\
\hline Poland & 0.821 & 75 & 0.865 & 78.1 & 0.044 & 3.1 \\
\hline Portugal & 0.816 & 90 & 0.847 & 90.9 & 0.031 & 0.9 \\
\hline Qatar & 0.834 & 98.2 & 0.856 & 89.6 & 0.022 & -8.6 \\
\hline Romania & 0.786 & 78.2 & 0.811 & 77.1 & 0.025 & -1.1 \\
\hline Russian Federation & 0.788 & 68.6 & 0.816 & 79.3 & 0.028 & 10.7 \\
\hline Singapore & 0.895 & 86.7 & 0.932 & 87.8 & 0.037 & 1.1 \\
\hline Slovakia & 0.84 & 74.4 & 0.855 & 74.7 & 0.015 & 0.3 \\
\hline Slovenia & 0.892 & 83.2 & 0.896 & 85 & 0.004 & 1.8 \\
\hline
\end{tabular}


Table 2 (continued)

\begin{tabular}{|c|c|c|c|c|c|c|}
\hline \multirow[t]{2}{*}{ Country } & \multicolumn{2}{|l|}{2012} & \multicolumn{2}{|l|}{2018} & \multicolumn{2}{|c|}{ Transitions in a decade } \\
\hline & HDI & Survival & $\mathrm{HDI}$ & Survival & $\Delta_{\mathrm{HDI}}$ & $\Delta_{\text {survival }}$ \\
\hline South Africa & 0.629 & 38.6 & 0.699 & 37.8 & 0.070 & -0.8 \\
\hline Spain & 0.885 & 90.4 & 0.891 & 89.7 & 0.006 & -0.7 \\
\hline Sweden & 0.916 & 90.1 & 0.933 & 90.7 & 0.017 & 0.6 \\
\hline Switzerland & 0.913 & 88.6 & 0.944 & 89.2 & 0.031 & 0.6 \\
\hline Thailand & 0.69 & 71.8 & 0.755 & 68 & 0.065 & -3.8 \\
\hline Turkey & 0.722 & 81.2 & 0.791 & 83.8 & 0.069 & 2.6 \\
\hline United Kingdom & 0.875 & 86.7 & 0.922 & 88.7 & 0.047 & 2 \\
\hline United States of America & 0.937 & 98.1 & 0.924 & 97.4 & -0.013 & -0.7 \\
\hline Uruguay & 0.792 & 84.7 & 0.804 & 86.5 & 0.012 & 1.8 \\
\hline
\end{tabular}

A total of 57 countries with survival rates available in both years; HDI, Human Development Index

However, we could not deny the overdiagnosis associated with PSA screening, which might also help to decrease mortality rates of individuals identified with prostate cancer. Some new biomarkers sparing those who overdiagnosed are under development (e.g., PCA3 or TMPRSS$E R G$ fusions) [25]. Secondly, the delivery of urologic oncology care is susceptible to regional variation. Access to effective radiation equipment and neoadjuvant hormonal therapy is linked to a country's wealth. Globally, there is a mismatch of radiation treatment resources to need, with nearly 4,000 radiation units in the United States and fewer than 300 in sub-Saharan Africa, a region with more than twice the population [26]; up to 36 countries worldwide have even no radiation capabilities [27]. Advances in immunotherapy and robotic surgery, though promising, are not feasible or affordable for generalized application in settings with limited health care resources [28-30]. Individuals in countries with higher HDI possessed heightened awareness and more positive preventative measures against prostate cancer such as smoking cessation and healthy diet.

Multiple studies have reported that the detected cases of prostate cancer from 1990 to 2010 were increasing rapidly, which could also be attributed to the era of PSA testing and ultrasonography, as well as aging population $[2,31]$. However, incidence of prostate cancer was on its downhill from 2012 to 2018 . The 2012 recommendation against the routine use of PSA testing by the US Preventive Services Task Force (USPSTF) may have partly driven trends downward [32]. American Urological Association (AUA) stated in 2013 update that routine screening of men aged 40-54 years and men with less than a 10 - to 15- year life expectancy was not recommended [33]. Meanwhile, our analysis revealed that from 2012 to 2018, the integral worldwide HDI values increased, along with the decline in MIRs and improvement in survival of prostate cancer. Scientific advances have resulted in rapidly growing medical technology and treatment strategies. The development of laparoscopic and robotic surgery, especially the da Vinci Surgical System (Intuitive Surgical, Sunnyvale, CA), has offered a less invasive approach while ensuring oncological remission and expected survival [28]. Meanwhile, novel approaches like immune checkpoint blockades targeting programmed cell death protein 1 (PD-1) or its ligand PD-L1 have also emerged as powerful methods against tumor progression, relapse, and metastasis [29, 30].

\section{Bladder cancer}

Higher incidence rates of bladder cancer could be observed in more developed countries, especially in Southern and Western Europe. The rates were positively correlated with HDI $(p<0.0001)$. Chemical or environmental exposures are major risk factors for bladder cancer, including smoking, obesity, alcohol drinking and red-meat consumption [34, 35, 37]. These risk factors have been reported by the World Health Organization as alarmingly high across Europe [36, 38, 39]. Other likely reason is widespread practice of initial assessment in more developed regions [35, 37]. However, mortality rates of bladder cancers did not follow those of incidence. MIR of bladder cancer appeared to be high in less developed regions. The correlation between MIR and HDI was moderately strong $(p<0.0001)$. Higher-quality medical care and better health awareness were possessed in highly developed areas, as stated in Prostate Cancer.

From 2012 to 2018, patients went in declines in both incidence and MIR of bladder cancer worldwide. Primary prevention of tobacco use is the most effective strategy for bladder cancer prophylaxis [23, 40]. Thus, decreasing incidence and earlier diagnosis, improved endoscopic system for cystoscopic surveillance [41], robotic surgery 
with less invasive injury [42], better intravesical therapy, such as the Bacillus Calmette-Guerin (BCG) and updated chemotherapy [34] and targeting therapy all contributed to bladder cancer outcomes improvement [43].

\section{Kidney cancer}

The incidence of kidney cancer was the highest in very high HDI countries, and correlated positively with country-specific HDI $(r=0.816, p<0.0001)$. Similarly, higher prevalence of risk factors such as obesity, hypertension, diabetes and smoking played a role in the increased incidence of kidney cancer in developed countries [44-50]. Furthermore, the frequency and quality of cross-sectional imaging tend to be higher in developed nations [23]. Similarly, MIR of kidney cancer negatively correlated with certain national HDI [50].

The global burden and MIR of kidney cancer stagnated or decreased in the majority of countries examined in this study from 2012 to 2018 . As discussed, more developed preventative efforts and treating methods could lead to a decrease in cancer incidence and mortality.

There are some limitations to our study. First, cancer registration in relatively less-developed nations could suffer from higher chance of under-reporting due to limited communication infrastructure and less robust recording system; low income and lower willingness to utilize healthcare services; relative lack of clinical services and investigation tests. GLOBOCAN and CONCORD-3 often extrapolates data for certain developing nations based on data from subnational areas or major cities. Second, discrepancies between the reliability of incidence and mortality reporting limit MIR interpretation, as mortality data are generally more accurate than incidence. Although we exclude extreme values $(0,1$, or $>1)$ of MIR, there is no way to correct this bias in our analysis. Third, we could not establish cause-and-effect relationships in correlational analysis.

\section{Conclusion}

In conclusion, HDI values are significantly correlated with urologic cancer incidence, MIRs and survival rates. More developed countries are more likely to have higher incidence and mortality rates, but lower MIRs. From 2012 to 2018, new cases of urologic cancer have declined, with apparent improvement in clinical outcomes. However, we should not relax our vigilance since patients with urological cancer were older and more medically complex, and had more frequent health system contact [51], especially in developing countries where gains in life expectancy and screening prevalence are greater. Disparities in cancer health care should compel us to exert greater effort in improving awareness, universal health coverage, access to either publicly funded or affordable screening programs and treatment in low HDI countries.

\section{Supplementary Information}

The online version contains supplementary material available at https://doi. org/10.1186/s12894-022-00953-5.

Additional file 1. Fig. S1. Worldwide distribution of Urologic cancer burden in 2018. A total of 174 countries were included. (a), (c), (e) Agestandardized incidence (blue) and (b), (d), (f) age-standardized mortality (red) rates per 100,000 population of prostate cancer, bladder cancer, and kidney cancer, separately, indicated in a gradient color scale. Countries with data unavailable (light gray) were denoted.

\section{Acknowledgements}

Not applicable.

\section{Authors' contributions}

XX and YW: Conceptualization, Methodology, Validation, Visualization, Formal analysis, Investigation, Writing-original draft. SS: Conceptualization, Resources, Visualization. XZ: Methodology, Visualization, Software. SZ: Validation, Investigation. ZL: Methodology, Visualization, Software. NZ and YY: Methodology, Data curation, Validation, Investigation, Resources, Writing-review \& editing, Funding acquisition. All authors read and approved the final manuscript.

\section{Funding}

This work was financially supported by the Zhejiang Provincial Natural Science Foundation (grant numbers Y18H050009), Zhejiang Provincial Science and Technology Department Public Welfare Projects (grant number LGC21H050001, LGF19H050006) and General research program of Zhejiang Provincial Department of health (grant number 2018265438).

\section{Availability of data and materials}

The incidence and mortality estimates of urologic cancer were originally extracted from the GLOBOCAN database (http://gco.iarc.fr) maintained by the International Agency for Research on Cancer (IARC). The public access to the database is open, and raw data would be available by contacting Dr. Zhang (nanzhang@zju.edu.cn).

\section{Declarations}

Ethics approval and consent to participate

Not applicable.

Consent for publication

Not applicable.

\section{Competing interests}

The authors declare no potential conflicts of interest.

\section{Author details}

${ }^{1}$ Department of Urology, The Second Affiliated Hospital, Zhejiang University School of Medicine, Hangzhou 310009, China. ${ }^{2}$ Department of Hepatobiliary and Pancreatic Surgery, First Affiliated Hospital, Zhejiang University School of Medicine, Hangzhou 310003, China. ${ }^{3}$ Department of Urology, Renji Hospital, Shanghai Jiao Tong University School of Medicine, Shanghai 200127, China.

Received: 5 August 2021 Accepted: 4 January 2022

Published online: 10 January 2022

References

1. Bray F, Ferlay J, Soerjomataram I, Siegel RL, Torre LA, Jemal A. Global cancer statistics 2018: GLOBOCAN estimates of incidence and mortality worldwide for 36 cancers in 185 countries. CA Cancer J Clin. 2018;68(6):394-424. https://doi.org/10.3322/caac.21492. 
2. Dy GW, Gore JL, Forouzanfar MH, Naghavi M, Fitzmaurice C. Global Burden of Urologic Cancers, 1990-2013. Eur Urol. 2017;71(3):437-46. https:// doi.org/10.1016/j.eururo.2016.10.008.

3. Loughlin KR. The future of urologic cancer care in the United States: our finest hour or a bridge too far. Urol Oncol. 2010;28(6):581-4. https://doi. org/10.1016/j.urolonc.2010.08.016.

4. Pang C, Guan Y, Li H, Chen W, Zhu G. Urologic cancer in China. Jpn J Clin Oncol. 2016;46(6):497-501. https://doi.org/10.1093/jjco/hyw034.

5. Umbas R, Safriadi F, Mochtar CA, Djatisoesanto W, Hamid AR. Urologic cancer in Indonesia. Jpn J Clin Oncol. 2015;45(8):708-12. https://doi.org/ 10.1093/jjco/hyv066.

6. Akaza H. Urologic cancer in Japan: role of Japan at the frontier of issues in Asia. Jpn J Clin Oncol. 2016;46(1):23-30. https://doi.org/10.1093/jjco/ hyv123.

7. Hung CF, Yang CK, Ou YC. Urologic cancer in Taiwan. Jpn J Clin Oncol. 2016;46(7):605-9. https://doi.org/10.1093/jjco/hyw038.

8. Lojanapiwat B. Urologic cancer in Thailand. Jpn J Clin Oncol. 2015;45(11):1007-15. https://doi.org/10.1093/jjco/hyv125.

9. Koo KC, Lee KS, Chung BH. Urologic cancers in Korea. Jpn J Clin Oncol. 2015;45(9):805-11. https://doi.org/10.1093/jjco/hyv096.

10. Hancock T. Health, human development and the community ecosystem: three ecological models. Health Promot Int. 1993;8(1):41-7. https://doi. org/10.1093/heapro/8.1.41.

11. United Nations Development Programme. Human Development Indices and Indicators, 2018 Statistical Update. (2018). http://hdr.undp.org/en/ 2018-update.

12. Hu QD, Zhang Q, Chen W, Bai XL, Liang TB. Human development index is associated with mortality-to-incidence ratios of gastrointestinal cancers. World J Gastroenterol. 2013;19(32):5261-70. https://doi.org/10.3748/wjg. v19.132.5261.

13. Fidler MM, Bray F. Global cancer inequalities. Front Oncol. 2018:8:293. https://doi.org/10.3389/fonc.2018.00293.

14. Hassanipour-Azgomi S, Mohammadian-Hafshejani A, Ghoncheh M, Towhidi F, Jamehshorani S, Salehiniya H. Incidence and mortality of prostate cancer and their relationship with the Human Development Index worldwide. Prostate Int. 2016;4(3):118-24. https://doi.org/10.1016/j.prnil. 2016.07.001.

15. Pakzad R, Mohammadian-Hafshejani A, Ghoncheh M, Pakzad I, Salehiniya $H$. The incidence and mortality of prostate cancer and its relationship with development in Asia. Prostate Int. 2015;3(4):135-40. https://doi.org/ 10.1016/j.prnil.2015.09.001.

16. Schneiderman MA (1968) Cancer Incidence in Five Continents: A Technical Report. Richard Doll, Peter Payne, and John Waterhouse (eds) New York: Springer-Verlag, 1966244 pp \$950 28 (4):804-804

17. Allemani C, Matsuda T, Di Carlo V, Harewood R, Matz M, Niksic M, Bonaventure A, Valkov M, Johnson CJ, Esteve J, Ogunbiyi OJ, Azevedo ESG, Chen WQ, Eser S, Engholm G, Stiller CA, Monnereau A, Woods RR, Visser O, Lim GH, Aitken J, Weir HK, Coleman MP, Group CW. Global surveillance of trends in cancer survival 2000-14 (CONCORD-3): analysis of individual records for 37513025 patients diagnosed with one of 18 cancers from 322 population-based registries in 71 countries. Lancet. 2018;391(10125):1023-75. https://doi.org/10.1016/S0140-6736(17) 33326-3.

18. Corazziari I, Quinn M, Capocaccia R. Standard cancer patient population for age standardising survival ratios. Eur J Cancer (Oxford, England: 1990). 2004;40(15):2307-16. https://doi.org/10.1016/j.ejca.2004.07.002.

19. Hebert JR, Daguise VG, Hurley DM, Wilkerson RC, Mosley CM, Adams SA, Puett R, Burch JB, Steck SE, Bolick-Aldrich SW. Mapping cancer mortalityto-incidence ratios to illustrate racial and sex disparities in a high-risk population. Cancer. 2009;115(11):2539-52. https://doi.org/10.1002/cncr. 24270.

20. Berkson J, Gage RP. Survival curve for cancer patients following treatment. J Am Stat Assoc. 1952;47(259):501-15. https://doi.org/10.1080/01621459. 1952.10501187

21. Kvale R, Auvinen A, Adami HO, Klint A, Hernes E, Moller B, Pukkala E, Storm HH, Tryggvadottir L, Tretli S, Wahlqvist R, Weiderpass E, Bray F. Interpreting trends in prostate cancer incidence and mortality in the five Nordic countries. J Natl Cancer Inst. 2007;99(24):1881-7. https://doi.org/ 10.1093/jnci/djm249.

22. Zhou CK, Check DP, Lortet-Tieulent J, Laversanne M, Jemal A, Ferlay J, Bray F, Cook MB, Devesa SS. Prostate cancer incidence in 43 populations worldwide: an analysis of time trends overall and by age group. Int J Cancer. 2016;138(6):1388-400. https://doi.org/10.1002/ijc.29894.

23. Greiman AK, Rosoff JS, Prasad SM. Association of Human Development Index with global bladder, kidney, prostate and testis cancer incidence and mortality. BJU Int. 2017;120(6):799-807. https://doi.org/10.1111/bju. 13875.

24. Rebbeck TR, Devesa SS, Chang BL, Bunker CH, Cheng I, Cooney K, Eeles R, Fernandez P, Giri VN, Gueye SM, Haiman CA, Henderson BE, Heyns CF, Hu $\mathrm{JJ}$, Ingles SA, Isaacs W, Jalloh M, John EM, Kibel AS, Kidd LR, Layne P, Leach RJ, Neslund-Dudas C, Okobia MN, Ostrander EA, Park JY, Patrick AL, Phelan CM, Ragin C, Roberts RA, Rybicki BA, Stanford JL, Strom S, Thompson IM, Witte J, Xu J, Yeboah E, Hsing AW, Zeigler-Johnson CM. Global patterns of prostate cancer incidence, aggressiveness, and mortality in men of African descent. Prostate Cancer. 2013;2013: 560857. https://doi.org/10. 1155/2013/560857

25. Cuzick J, Thorat MA, Andriole G, Brawley OW, Brown PH, Culig Z, Eeles RA, Ford LG, Hamdy FC, Holmberg L, llic D, Key TJ, La Vecchia C, Lilja H, Marberger M, Meyskens FL, Minasian LM, Parker C, Parnes HL, Perner S, Rittenhouse H, Schalken J, Schmid HP, Schmitz-Drager BJ, Schroder FH, Stenzl A, Tombal B, Wilt TJ, Wolk A. Prevention and early detection of prostate cancer. Lancet Oncol. 2014;15(11):e484-492. https://doi.org/10. 1016/s1470-2045(14)70211-6.

26. International Atomic Energy Agency: DIRAC (Directory of Radiotherapy Centres). http://nucleus.iaea.org/HHW/m/DBStatistics/DIRAC/

27. Efstathiou JA, Heunis M, Karumekayi T, Makufa R, Bvochora-Nsingo M, Gierga DP, Suneja G, Grover S, Kasese J, Mmalane M, Moffat H, von Paleske A, Makhema J, Dryden-Peterson S. Establishing and delivering quality radiation therapy in resource-constrained settings: the story of Botswana. J Clin Oncol. 2016;34(1):27-35. https://doi.org/10.1200/jco.2015.62.8412.

28. Forsmark A, Gehrman J, Angenete E, Bjartell A, Bjorholt I, Carlsson S, Hugosson J, Marlow T, Stinesen-Kollberg K, Stranne J, Wallerstedt A, Wiklund P, Wilderang U, Haglind E. Health economic analysis of open and robot-assisted laparoscopic surgery for prostate cancer within the prospective multicentre LAPPRO trial. Eur Urol. 2018;74(6):816-24. https:// doi.org/10.1016/j.eururo.2018.07.038.

29. Abida W, Cheng ML, Armenia J, Middha S, Autio KA, Vargas HA, Rathkopf D, Morris MJ, Danila DC, Slovin SF, Carbone E, Barnett ES, Hullings M, Hechtman JF, Zehir A, Shia J, Jonsson P, Stadler ZK, Srinivasan P, Laudone VP, Reuter V, Wolchok JD, Socci ND, Taylor BS, Berger MF, Kantoff PW, Sawyers CL, Schultz N, Solit DB, Gopalan A, Scher HI. Analysis of the prevalence of microsatellite instability in prostate cancer and response to immune checkpoint blockade. JAMA Oncol. 2018. https://doi.org/10, 1001/jamaoncol.2018.5801.

30. Zhao SG, Lehrer J, Chang SL, Das R, Erho N, Liu Y, Sjostrom M, Den RB, Freedland SJ, Klein EA, Karnes RJ, Schaeffer EM, Xu M, Speers C, Nguyen PL, Ross AE, Chan JM, Cooperberg MR, Carroll PR, Davicioni E, Fong L, Spratt DE, Feng FY. The immune landscape of prostate cancer and nomination of PD-L2 as a potential therapeutic target. J Natl Cancer Inst. 2018. https://doi.org/10.1093/jnci/djy141.

31. Bosetti C, Bertuccio P, Chatenoud L, Negri E, La Vecchia C, Levi F. Trends in mortality from urologic cancers in Europe, 1970-2008. Eur Urol. 2011;60(1):1-15. https://doi.org/10.1016/j.eururo.2011.03.047.

32. Grossman DC, Curry SJ, Owens DK, Bibbins-Domingo K, Caughey AB, Davidson KW, Doubeni CA, Ebell M, Epling JW Jr, Kemper AR, Krist AH, Kubik M, Landefeld CS, Mangione CM, Silverstein M, Simon MA, Siu AL, Tseng CW. Screening for prostate cancer: US preventive services task force recommendation statement. JAMA. 2018;319(18):1901-13. https:// doi.org/10.1001/jama.2018.3710.

33. Carter HB, Albertsen PC, Barry MJ, Etzioni R, Freedland SJ, Greene $\mathrm{KL}$, Holmberg L, Kantoff P, Konety BR, Murad MH, Penson DF, Zietman AL. Early detection of prostate cancer: AUA Guideline. J Urol. 2013;190(2):419-26. https://doi.org/10.1016/j.juro.2013.04.119.

34. Kaufman DS, Shipley WU, Feldman AS. Bladder cancer. Lancet. 2009;374(9685):239-49. https://doi.org/10.1016/s0140-6736(09)60491-8.

35. Wong MCS, Fung FDH, Leung C, Cheung WWL, Goggins WB, Ng CF. The global epidemiology of bladder cancer: a joinpoint regression analysis of its incidence and mortality trends and projection. Sci Rep. 2018;8(1):1129. https://doi.org/10.1038/s41598-018-19199-z.

36. Schmitz-Drager BJ, Droller M, Lokeshwar VB, Lotan Y, Hudson MA, van Rhijn BW, Marberger MJ, Fradet Y, Hemstreet GP, Malmstrom PU, Ogawa O, Karakiewicz PI, Shariat SF. Molecular markers for bladder cancer 
screening, early diagnosis, and surveillance: the WHO/ICUD consensus. Urol Int. 2015;94(1):1-24. https://doi.org/10.1159/000369357.

37. Silverman DMA, Devasa S. Bladder cancer. In: Schottenfeld DFJJ, editor. Cancer epidemiology and prevention. 2nd ed. New York: Oxford University Press; 1996. p. 1156-79.

38. Bilano V, Gilmour S, Moffiet T, d'Espaignet ET, Stevens GA, Commar A, Tuyl F, Hudson I, Shibuya K. Global trends and projections for tobacco use, 1990-2025: an analysis of smoking indicators from the WHO Comprehensive Information Systems for Tobacco Control. Lancet. 2015;385(9972):966-76. https://doi.org/10.1016/s0140-6736(15)60264-1.

39. Kauppinen T, Toikkanen J, Pedersen D, Young R, Ahrens W, Boffetta P, Hansen J, Kromhout H, Maqueda Blasco J, Mirabelli D, de la Orden-Rivera V, Pannett B, Plato N, Savela A, Vincent R, Kogevinas M. Occupational exposure to carcinogens in the European Union. Occup Environ Med. 2000;57(1):10-8.

40. Organization. WH WHO Framework Convention on Tobacco Control. Accessed 06/07/2017

41. Zlatev DV, Altobelli E, Liao JC (2015) Advances in imaging technologies in the evaluation of high-grade bladder cancer. The Urologic clinics of North America 42 (2):147-157, vii. doi:https://doi.org/10.1016/j.ucl.2015. 01.001

42. Parekh DJ, Reis IM, Castle EP, Gonzalgo ML, Woods ME, Svatek RS, Weizer AZ, Konety BR, Tollefson M, Krupski TL, Smith ND, Shabsigh A, Barocas DA, Quek ML, Dash A, Kibel AS, Shemanski L, Pruthi RS, Montgomery JS, Weight CJ, Sharp DS, Chang SS, Cookson MS, Gupta GN, Gorbonos A, Uchio EM, Skinner E, Venkatramani V, Soodana-Prakash N, Kendrick $\mathrm{K}$, Smith JA Jr, Thompson IM. Robot-assisted radical cystectomy versus open radical cystectomy in patients with bladder cancer (RAZOR): an open-label, randomised, phase 3, non-inferiority trial. Lancet. 2018;391(10139):2525-36. https://doi.org/10.1016/s0140-6736(18) 30996-6.

43. Daizumoto K, Yoshimaru T, Matsushita Y, Fukawa T, Uehara H, Ono M, Komatsu M, Kanayama HO, Katagiri T. A DDX31/Mutant-p53/EGFR axis promotes multistep progression of muscle-invasive bladder cancer. Can Res. 2018;78(9):2233-47. https://doi.org/10.1158/0008-5472.can-17-2528.

44. Chow WH, Gridley G, Fraumeni JF Jr, Jarvholm B. Obesity, hypertension, and the risk of kidney cancer in men. N Engl J Med. 2000;343(18):130511. https://doi.org/10.1056/nejm200011023431804.

45. Zucchetto A, Dal Maso L, Tavani A, Montella M, Ramazzotti V, Talamini R, Canzonieri V, Garbeglio A, Negri E, Franceschi S, La Vecchia C. History of treated hypertension and diabetes mellitus and risk of renal cell cancer. Ann Oncol. 2007;18(3):596-600. https://doi.org/10.1093/annonc/mdl438.

46. Sanfilippo KM, McTigue KM, Fidler CJ, Neaton JD, Chang Y, Fried LF, Liu $\mathrm{S}$, Kuller LH. Hypertension and obesity and the risk of kidney cancer in 2 large cohorts of US men and women. Hypertension (Dallas Tex: 1979). 2014;63(5):934-41. https://doi.org/10.1161/hypertensionaha.113.02953.

47. Graff RE, Sanchez A, Tobias DK, Rodriguez D, Barrisford GW, Blute ML, Li Y, Sun Q, Preston MA, Wilson KM, Cho E. Type 2 diabetes in relation to the risk of renal cell carcinoma among men and women in two large prospective cohort studies. Diabetes Care. 2018;41(7):1432-7. https://doi. org/10.2337/dc17-2518.

48. Melgarejo JD, Maestre GE, Thijs L, Asayama K, Boggia J, Casiglia E, Hansen TW, Imai Y, Jacobs L, Jeppesen J, Kawecka-Jaszcz K, Kuznetsova T, Li Y, Malyutina S, Nikitin Y, Ohkubo T, Stolarz-Skrzypek K, Wang JG, Staessen JA (2017) Prevalence, treatment, and control rates of conventional and ambulatory hypertension across 10 populations in 3 continents. Hypertension (Dallas, Tex: 1979) 70 (1):50-58. https://doi.org/10.1161/hyper tensionaha.117.09188

49. King H, Aubert RE, Herman WH. Global burden of diabetes, 1995-2025: prevalence, numerical estimates, and projections. Diabetes Care. 1998;21(9):1414-31.

50. Znaor A, Lortet-Tieulent J, Laversanne M, Jemal A, Bray F. International variations and trends in renal cell carcinoma incidence and mortality. Eur Urol. 2015;67(3):519-30. https://doi.org/10.1016/j.eururo.2014.10.002.

51. Garg T, Young AJ, Kost KA, Danella JF, Larson S, Nielsen ME, Kirchner HL. Burden of multiple chronic conditions among patients with urological cancer. J Urol. 2018;199(2):543-50. https://doi.org/10.1016/j.juro.2017.08. 005.

\section{Publisher's Note}

Springer Nature remains neutral with regard to jurisdictional claims in published maps and institutional affiliations.
Ready to submit your research? Choose BMC and benefit from:

- fast, convenient online submission

- thorough peer review by experienced researchers in your field

- rapid publication on acceptance

- support for research data, including large and complex data types

- gold Open Access which fosters wider collaboration and increased citations

- maximum visibility for your research: over $100 \mathrm{M}$ website views per year

At BMC, research is always in progress.

Learn more biomedcentral.com/submissions 